\title{
Stimulation of $\alpha 1$ (I) Procollagen Gene Expression in NIH-3T3 Cells by the Human T Cell Leukemia Virus Type 1 (HTLV-1) Tax Gene
}

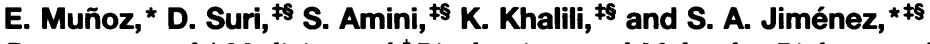 \\ Departments of ${ }^{*}$ Medicine and ${ }^{\ddagger}$ Biochemistry and Molecular Biology, and the ${ }^{\S}$ Jefferson Institute of Molecular Medicine, Jefferson \\ Medical College, Thomas Jefferson University, Philadelphia, Pennsylvania 19107
}

\begin{abstract}
The mechanisms that regulate the expression of genes encoding extracellular matrix proteins in fibroblasts and other mesenchymal cells have remained elusive. Studies from several laboratories have indicated that Tax, a trans-regulatory protein from the human $T$ cell leukemia virus type $I$ not only augments viral gene expression but also triggers the expression of various cellular genes. Here, we examined the hypothesis that the expression of collagen genes may also be modulated by Tax. NIH-3T3 cells were simultaneously transfected with a Tax expressor plasmid and a chimeric construct containing regulatory sequences $(-804$ to $+42 \mathrm{bp})$ of the $\alpha 1(I)$ procollagen gene (COL1A1) promoter. The results indicated that the promoter activity of the -804 to +42 bp COL1A1 fragment increased up to 12 -fold in cells expressing Tax. Deletion analysis revealed that the region of COL1A1 encompassing nucleotides -174 to -84 contained the Tax-responsive elements. A gene segment encompassing nucleotides -187 to -67 , which contained this region, proved sufficient to confer Tax inducibility (2.5-fold) to a herpes simplex virus thymidine kinase promoter. Stably transfected NIH-3T3 cell clones that constitutively produce Tax displayed elevated levels of $\alpha 1$ (I) procollagen and fibronectin transcripts and increased production and accelerated processing of type I procollagen. These findings suggest that retroviral proteins may be involved in the pathogenesis of idiopathic diseases accompanied by collagen overproduction. (J. Clin. Invest. 1995. 96:2413-2420.) Key words: procollagen genes $\cdot$ tax protein $\cdot$ retroviruses $\cdot$ collagen gene expression • tissue fibrosis
\end{abstract}

\section{Introduction}

Systemic sclerosis and idiopathic pulmonary fibrosis are prototypes of a group of diseases characterized by the excessive accumulation of collagen and other connective tissue macromolecules in various tissues. The mechanisms responsible for the exaggerated fibrosis of affected organs in these diseases have remained elusive despite intensive investigations, although most

Address correspondence to Sergio A. Jiménez, Thomas Jefferson University, Bluemle Life Sciences Building, Room 509, 233 South 10th Street, Philadelphia, PA 19107. Phone: 215-955-5042; FAX: 215-9234649.

Received for publication 13 April 1994 and accepted in revised form 17 July 1995.

J. Clin. Invest.

(C) The American Society for Clinical Investigation, Inc.

$0021-9738 / 95 / 11 / 2413 / 08 \quad \$ 2.00$

Volume 96, November 1995, 2413-2420 studies indicate abnormalities in the regulation of expression of the genes encoding extracellular matrix proteins $(1,2)$.

The intimate mechanisms involved in the regulation of collagen gene expression under normal and pathologic conditions remain poorly understood (for review see reference 3 ). The possibility that viral transformation or expression of viral proteins in connective tissue cells may modulate the regulatory processes involved in the production of extracellular matrix proteins by these cells has been examined extensively. Early studies demonstrated that transformation of fibroblasts and chondrocytes with the Rous sarcoma virus resulted in marked inhibition of collagen production and in a change in the differentiated cellular phenotype regarding the collagen types produced (4-8). We previously described that transformation of embryonic chick vertebral chondrocytes by a temperature-sensitive mutant of Rous sarcoma virus caused a marked inhibition of type I collagen production and a concomitant increase in the production of fibronectin at the permissive temperature (8). Other studies that examined the effects of viral transformation on fibroblasts and other mesenchymal cells have indicated that, with few exceptions, viral transformation results in marked inhibition of collagen gene expression (9).

The HIV-1 Tat protein is a potent transactivator of viral (10), as well as of a number of endogenous genes including those encoding cytokines and growth factors $(11,12)$. We recently demonstrated that transfection of glioblastoma cells with the gene encoding the HIV-1 Tat protein resulted in increased expression of the genes encoding types I and III collagens and fibronectin (13). The purpose of the studies reported here was to examine the effects of expression of the human $\mathrm{T}$ cell leukemia virus type- 1 (HTLV-1 $)^{1}$ Tax protein, a more potent retroviral transactivator protein than Tat, on the expression of the $\alpha 1$ (I) procollagen gene (COL1A1) in NIH-3T3 cells. Our results showed that production of Tax protein in NIH-3T3 cells caused increased expression of COL1A1 and that these effects occurred at the level of transcription. We also demonstrated that the cis-acting elements within the $\alpha 1$ (I) procollagen promoter involved in Tax transactivation are contained within a region of the promoter encompassing nucleotides -174 to -84 with respect to the transcription initiation site. Furthermore, a gene segment, encompassing nucleotides -174 to -67 , which contained this region of the promoter, was able to confer Tax responsiveness when cloned upstream of a heterologous promoter linked to a chloramphenicol acetyltransferase (CAT) reporter gene.

\section{Methods}

Cells and plasmids. NIH-3T3 cells were used in all the experiments. The cells were grown in DME supplemented with $10 \%$ calf serum, $1 \%$

1. Abbreviations used in this paper: CAT, chloramphenicol acetyltransferase; HSV, herpes simplex virus; HTLV-1, human T-cell leukemia virus type I; LTR, long terminal repeat; tk, thymidine kinase. 




B

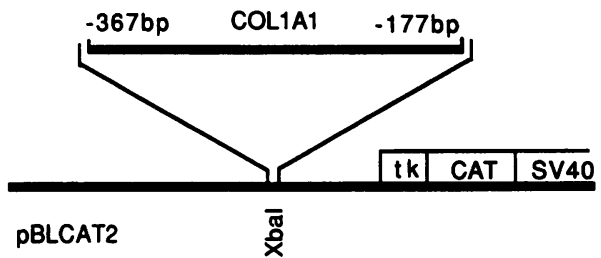

Figure 1. Schematic diagram of COL1A1 promoter-HSV tk-CAT constructs. The constructs were prepared as described in Methods. $(A)$ pAC182 contains COL1A1 nucleotides -187 to -67 (Tax-responsive region) cloned immediately upstream of the heterologous HSV tk promoter and the CAT reporter gene. $(B)$ pAC 330 contains COL1A1 nucleotides -367 to -177 (Tax-unresponsive region) cloned immediately upstream of the HSV tk promoter and the CAT reporter gene.

vitamins, $1 \%$ glutamine, $1 \%$ penicillin-streptomycin, and $0.4 \%$ fungizone. The plasmids used were: long terminal repeat (LTR)-Tax, a recombinant containing the HTLV-1 Tax gene under the control of the LTR of HTLV-1 (14); pU3R-CAT, composed of the U3 and R regions of the HTLV-1 LTR cloned upstream of the CAT gene (15); pNeo, a plasmid which contains the neomycin resistance gene cloned downstream of the bovine papilloma virus promoter (16); and the constructs pAC171, pAC198, pAC199, pAC200, pAC204, and pAC205 which are progressive 5' deletions of the human $\alpha 1$ (I) procollagen gene promoter each cloned upstream of the CAT reporter gene. All the pAC constructs end at nucleotide +42 to assure transcription in a proper reading frame and their 5 ' ends are at $-804,-675,-463,-369,-174$, and $-84 \mathrm{bp}$ respectively. These recombinant constructs have been described in detail previously (17). The construct pAC182, was generated by PCR amplification of the region of the human $\alpha 1$ (I) procollagen gene promoter encompassing nucleotides -187 to -67 . This region was cloned into

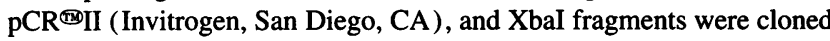
immediately upstream of the herpes simplex virus (HSV) thymidine kinase (tk) promoter of pBLCAT2 (18). The construct pAC330 was generated by PCR amplification of the upstream COL1A1 promoter region encompassing nucleotides -367 to -177 followed by similar cloning steps as those used to obtain pAC182. The plasmids pAC182 and pAC330 were sequenced to confirm their sequence and their orientation relative to the tk promoter. A schematic diagram of these two constructs is shown in Fig. 1.

Transfections and CAT assays. For transient transfections, NIH-3T3 cells were plated at a density of $3 \times 10^{5}$ cells per 60 -mm culture dish and $24 \mathrm{~h}$ later were transfected by the calcium phosphate/DNA coprecipitation method (19). In transient transfection assays, $2.5 \mu \mathrm{g}$ of each pAC plasmid were cotransfected with 2.5-10 $\mu \mathrm{g}$ of LTR-Tax plasmid. As a control pU3R-CAT $(0.25-0.5 \mu \mathrm{g})$ transfections in the absence or presence of LTR-tax were performed. $48 \mathrm{~h}$ after transfections, extracts were prepared using repeated freezing-thawing of the cells and CAT assays were performed on the extracts as described (20). For stable transfections, either $10 \mu \mathrm{g}$ of LTR-Tax plasmid plus $1 \mu \mathrm{g}$ of pNeo plasmid or $1 \mu \mathrm{g}$ of pNeo plasmid alone were used. The total
A
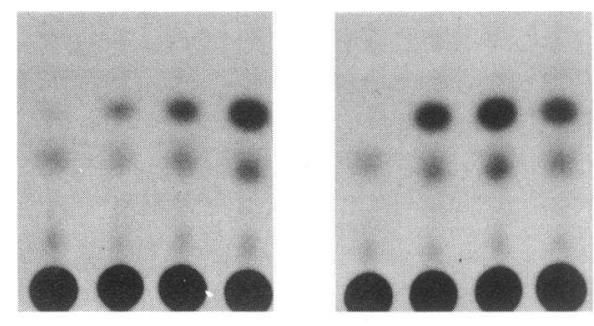

TAX ng

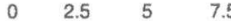

$\begin{array}{llll}0 & 2.5 & 5 & 7.5\end{array}$

$\mu \mathrm{g}$ TAX

pAC171

$(2.5 \mu \mathrm{g})$

$\ldots$ pU3R(HTLV1) _

$(0.18 \mu \mathrm{g})$

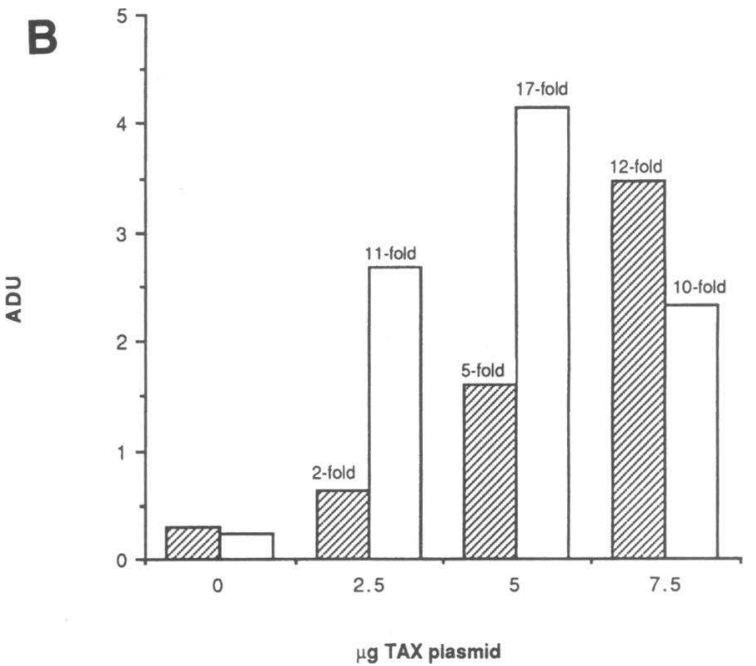

Figure 2. Transactivation of the COL1A1 promoter by transient transfection of NIH-3T3 cells with the LTR-Tax expressor plasmid. $(A)$ Transient transfection of NIH-3T3 cells with $2.5 \mu \mathrm{g}$ of plasmid pAC171 $(-804-+42$ of COL1A1 cloned upstream of the CAT gene) and increasing amounts of LTR-Tax plasmid (Tax). The chimeric plasmid pU3R-CAT containing the HTLV-1 gene regulatory region pU3R driving CAT was used as a control. $(B)$ Densitometric analysis of the acetylated forms of chloramphenicol. The bars represent arbitrary densitometric units $(A D U)$. pAC171; $\square, \mathrm{pU} 3 \mathrm{R}-\mathrm{CAT}$.

amount of DNA to be transfected was maintained constant at $15 \mu \mathrm{g}$ per $60-\mathrm{mm}$ culture dish or $20 \mu \mathrm{g}$ per $100-\mathrm{mm}$ culture dish by addition of salmon sperm DNA. The selection and maintenance of the neomycinresistant $\left(\mathrm{NeO}^{+}\right)$clones was made by supplementing the media with 400 $\mu \mathrm{g} / \mathrm{ml}$ Geneticin (G418 sulfate; Boehringer-Mannheim Biochemicals, Indianapolis, IN), as described previously (21).

RNA isolation and analysis. Total RNA from stable clones cultured in T175 flasks (Falcon, Becton Dickinson Labware, Lincoln Park, NJ) was extracted with guanidinium thiocyanate followed by ultracentrifugation in a $\mathrm{CsCl}$ gradient (22). $10 \mu \mathrm{g}$ of total RNA was electrophoresed in $1.2 \%$ agarose-formaldehyde gels, and after electrophoresis the gels were transferred to nitrocellulose membranes. The membranes were sequentially hybridized to ${ }^{32} \mathrm{P}$-labeled cDNAs for murine $\alpha 1$ (I) procollagen, fibronectin, and glutaraldehyde 3-phosphate dehydrogenase (GAPDH). These cDNAs have been described previously (23-25).

Protein analysis. Approximately $5 \times 10^{4}$ cells were seeded in triplicate in 24-well plates with $1 \mathrm{ml}$ of medium containing $400 \mu \mathrm{g} / \mathrm{ml}$ of G418 and were kept at $37^{\circ} \mathrm{C}$ in a $5 \% \mathrm{CO}_{2}$ moist atmosphere. When the cultures reached confluency, the media were supplemented with $50 \mu \mathrm{g} /$ $\mathrm{ml}$ of fresh ascorbic acid, and $24 \mathrm{~h}$ later, fresh media containing 100 $\mu \mathrm{g} / \mathrm{ml}$ of $\beta$-aminopropionitrile and $1.5 \mu \mathrm{Ci} / \mathrm{ml}$ of $\left[{ }^{14} \mathrm{C}\right]$ proline was added and the incubation continued for $24 \mathrm{~h}$. At the end of the incubation 
A

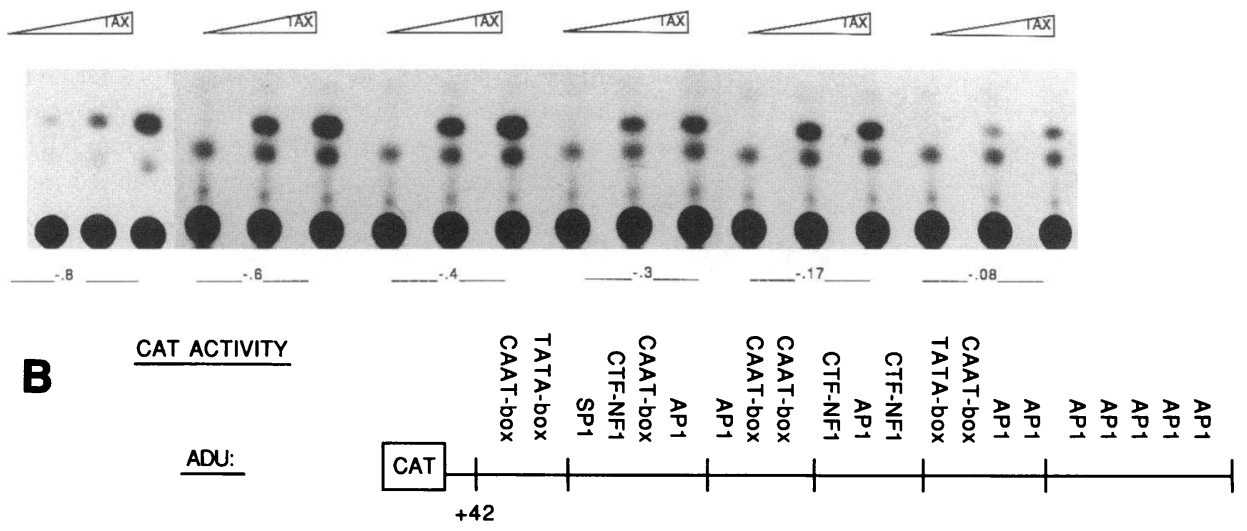

Figure 3. Effects of transient transfections of the LTR-Tax expressor plasmid on the CAT activity driven by deletion constructs of the COL1A1 promoter. ( $A$ ) Autoradiogram of CAT assays performed with extracts from NIH-3T3 cells that had been cotransfected with $2.5 \mu \mathrm{g}$ each of one of various deletion constructs of COL1A1 with 5 ' endpoints at $-804,-675$, $-463,-369,-174$, and -84 bp and increasing concentrations $(0,5.0,7.5$ -
PAC171 $\mu \mathrm{g}$ ) of the LTR-Tax plasmid (Tax). $(B)$ Densitometric scanning of the autoradiograms. The bars indicate arbitrary densitometric units $(A D U)$ for the experiment in which $7.5 \mu \mathrm{g}$ of LTR-Tax were used. The regulatory sequences present in the COLlAl promoter ( -804 to $+42 \mathrm{bp})$ and a representation of the various deletion derivatives of the COL1A1 promoter used are also shown. ${ }^{*} P<0.001$.

period, the media and the cells were separately harvested and protease inhibitors were added to yield final concentrations of $5 \mathrm{mM}$ EDTA, 0.2 mM PMSF, $5 \mathrm{mM} N$-ethylmaleimide, and $1 \mathrm{mM} p$-aminobenzamidine hydrochloride. Cell layers were disrupted in $300 \mu \mathrm{l}$ of $4 \mathrm{M}$ guanidinium thiocyanate solution and brought to $1 \mathrm{ml}$ with distilled water. Aliquots of media and cell suspensions were dialyzed overnight against running water to remove the unincorporated isotope. Total incorporation of $\left[{ }^{14} \mathrm{C}\right]$ proline was measured in a scintillation spectrometer and total collagenous proteins were determined by a collagenase digestion assay (26). The labeled proteins in media and cell layer suspensions were analyzed by SDS-PAGE under reducing conditions, and the gels were processed by fluorography and subsequent densitometry.

\section{Results}

Transactivation of COL1A1 promoter by HTLV-1 Tax. To investigate the effect of Tax on the expression of the COL1A1 gene, NIH-3T3 cells were transfected simultaneously with the LTRTax plasmid, a Tax expressor plasmid, and the pAC171 plasmid containing -804 to +42 bp of the COL1A1 promoter cloned upstream of the CAT reporter gene. The pU3R-CAT plasmid in which the CAT gene is driven by the HTLV-1 promoter was cotransfected along with the LTR-Tax plasmid as a positive control. $48 \mathrm{~h}$ after transfection the crude protein extracts were assayed for CAT activity. The results presented in Fig. 2 demonstrate that the CAT activity driven by the -804 to +42 bp $\alpha 1$ (I) procollagen promoter ( $\mathrm{pAC171}$ ) progressively increased in response to increasing concentrations of the LTR-Tax plasmid. The dose-dependent promoter activation induced by Tax reached a maximal level of 12 -fold when $7.5 \mu \mathrm{g}$ of LTR-Tax construct was used. Cotransfection with higher concentrations of the Tax plasmid resulted in a decrease in CAT activity driven by the $\alpha 1$ (I) procollagen gene promoter (data not shown). The results of cotransfections of pU3R-CAT, the positive control plasmid used along with the LTR-Tax plasmid, showed a maximal increase in activity of 17-fold when $5 \mu \mathrm{g}$ of LTR-Tax plasmid was used. Cotransfection with higher concentrations of LTR-Tax resulted in lower expression of the pU3R-CAT construct. The basal CAT activity driven by this promoter was similar to that observed in cells transfected with pAC171 alone. These results indicate that expression of Tax protein in the NIH-3T3 cells by transfection of the Tax expressor plasmid, as documented in parallel experiments by transactivation of pU3RCAT, caused a dose-dependent stimulation of the expression of the COL1A1 gene.

Identification of COLlA1 promoter regions involved in Tax transactivation. To determine the regions of the COL1A1 promoter that are important for the response to Tax transactivation, deletion mutants of the promoter with various $5^{\prime}$ endpoints (from -804 to $-84 \mathrm{bp}$ ) cloned upstream of the CAT reporter gene were cotransfected into NIH-3T3 cells along with the LTRTax plasmid. The results from seven separate experiments (Fig. 3 ) revealed no statistically significant differences between the CAT activities driven by constructs with 5 ' end points at -804 , $-675,-463,-369$, or $-174 \mathrm{bp}$. However, further deletion of the promoter from -174 to -84 bp resulted in a marked decrease in CAT activity (55\% compared to the CAT activity driven by the -174 bp construct). These results were statistically significant $(P<0.001)$ and indicate that the most important sequences of the COL1A1 promoter involved in Tax transactivation are located within the region encompassing nucleotides -174 to -84 . However, it should be noted that the -84-bp construct showed some response to Tax, suggesting that additional cis-elements or a primary response element may be present in this region of the COL1A1 promoter. Examination of the relevant COL1A1 promoter sequences (Fig. $3 B$ ) sug- 
A



B

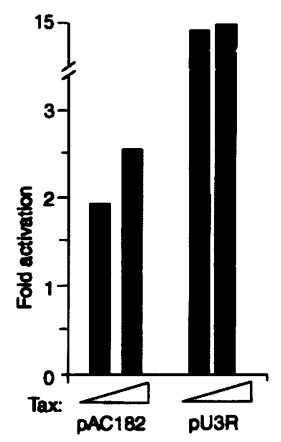

Figure 4. Effects of transient transfections of the LTR-Tax expressor plasmid on the CAT activity driven by the -187 to $-67 \mathrm{bp}$ region of COL1A1, linked to an HSV tk promoter. $(A)$ Autoradiogram of CAT assays performed with extracts from $\mathrm{NIH}$ 3T3 cells that had been cotransfected with $2.5 \mu \mathrm{g}$ of pAC182 (containing nucleotides -187 to -67 ), $2.5 \mu \mathrm{g}$ of pAC330 (containing nucletotides -367 to $-177), 2.5 \mu \mathrm{g}$ of pBLCAT2, or $0.5 \mu \mathrm{g}$ pU3RCAT and increasing concentrations $(0,5.0$, and $7.5 \mu \mathrm{g})$ of the LTR-Tax plasmid (Tax). (Arrow) Migration of acetylated chloramphenicol. $(B)$ Percent acetylation of chloramphenicol. gested that the decrease in CAT activity was likely due to removal of the promoter regions containing the consensus SP1, AP-1, and/or the proximal, but not the upstream, CTF-NF1 sequences or to removal of other not previously identified regulatory elements. To confirm that sequences within the COL1A1 promoter region from -174 to $-84 \mathrm{bp}$ were necessary and sufficient for Tax-inducible CAT expression, a fragment of the COL1A1 promoter ( -187 to $-67 \mathrm{bp}$ ) encompassing the Taxresponsive region was subcloned upstream of the HSV tk promoter-CAT transcription unit and was cotransfected into NIH3T3 cells along with the LTR-Tax plasmid. The results (Fig. 4), demonstrated an increase in CAT activity driven by the construct containing the COL1A1 promoter fragment encompassing the Tax-responsive region (pAC182) with increasing concentrations of transfected Tax and minimal Tax-transactivation of the tk promoter. The promoter activation induced by LTR-Tax cotransfection reached a maximum of 2.5 -fold. In contrast, there was no increase in CAT activity when the construct pAC330 (containing a Tax-unresponsive region of the promoter) was cotransfected with LTR-Tax. The results of cotransfections of pU3R-CAT and LTR-Tax plasmid showed a maximal increase in activity of 15 -fold. The basal CAT activity of the pAC182 was similar to that observed in cells transfected with the COL1A1 promoter construct pAC204 ( $5^{\prime}$ endpoint at $-174 \mathrm{bp}$ ) (data not shown).

Transactivation of HTLV-1 and COL1A1 promoters in Taxproducing stable cell lines. To examine further the role of Tax protein on collagen gene expression, Tax-producing NIH-3T3

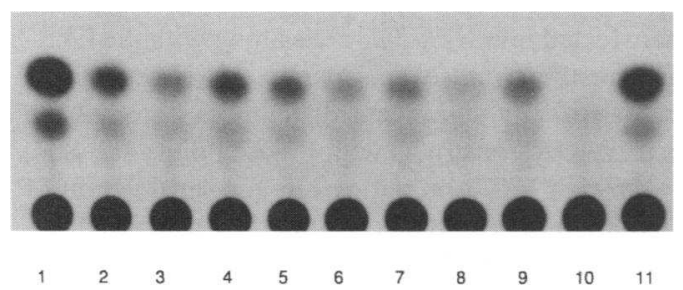

Figure 5. Transactivation of the HTLV-1 promoter in stable clones from NIH-3T3 cells transfected with the pNeo plasmid alone or with the LTR-Tax expressor plasmid plus the pNeo plasmid. (Lanes 1-9) Stable clones from cells transfected with $10 \mu \mathrm{g}$ of LTR-Tax plasmid plus 1 $\mu \mathrm{g}$ of pNeo plasmid, transiently transfected with the pU3R-CAT reporter plasmid. (Lane 10) Control neomycin-resistant clone, transiently transfected with the pU3R-CAT reporter plasmid. (Lane 11) Positive control NIH-3T3 cells cotransfected with the LTR-Tax plasmid and the pU3R-CAT reporter plasmid. stable clones were established by cotransfection of the LTRTax and the neomycin-resistance plasmid, pNeo. Several stable clones were obtained after neomycin selection. Expression of functional Tax in the selected clones was examined by transient expression of the HTLV-1 LTR. Of 46 clones established, 20 were positive for $\operatorname{Tax}(\operatorname{Tax}+)$ as illustrated for selected clones in Fig. 5. The morphology of representative clones of cells stably transfected with either LTR-Tax plus pNeo or pNeo alone is shown in Fig. 6. The control clones obtained by transfection
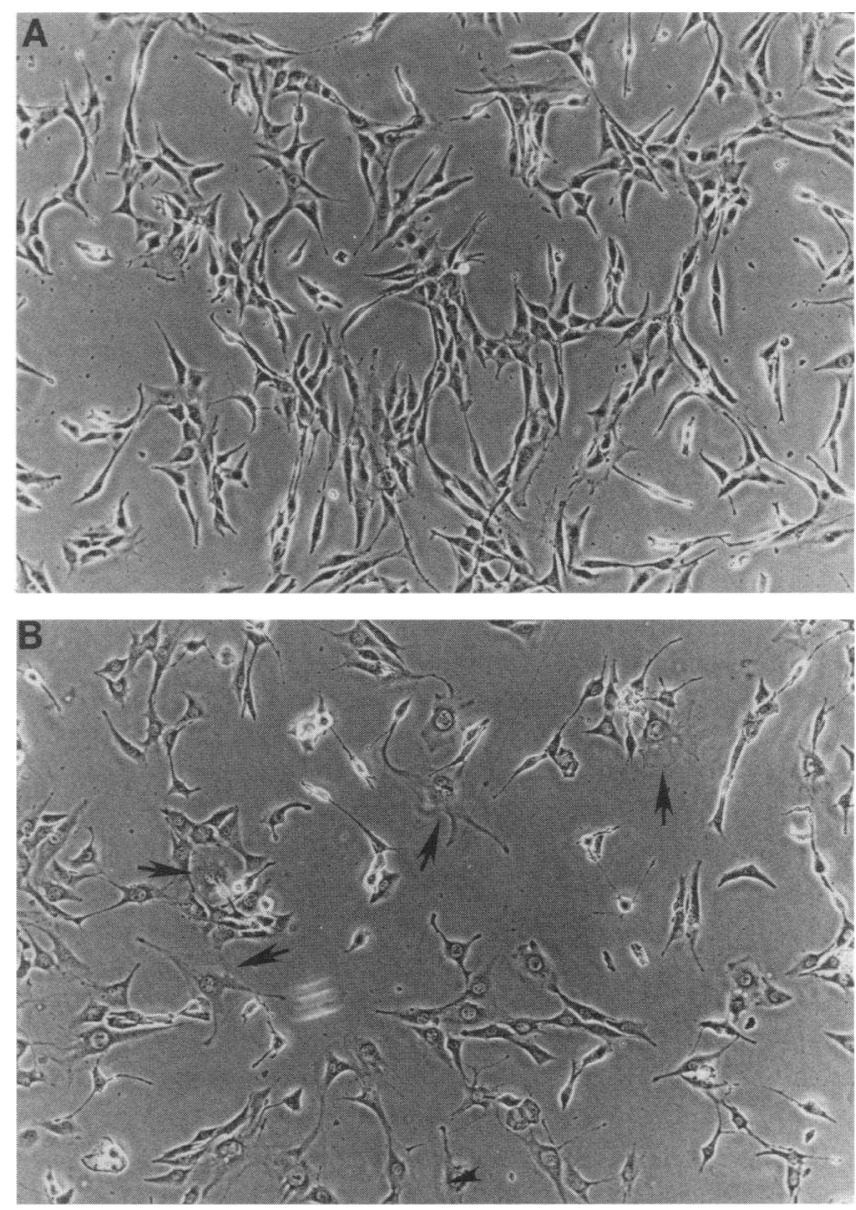

Figure 6. Morphology of stable clones. Dark-field morphologic appearance of cultures from NIH-3T3 cells transfected with the pNeo plasmid alone $(A)$ or with the LTR-Tax plasmid plus the pNeo plasmid $(B)$. 




NEO TAX+

pAC171

$(3 \mu \mathrm{g})$
Figure 7. Transactivation of COL1A1 promoter in stable clones. Transactivation of COL1A1 promoter in stable clones of NIH3T3 cells obtained by transfection with the pNeo plasmid alone (NEO) or of a stable clone obtained by transfection with the LTRTax plasmid plus the pNeo plasmid (TAX+).

with pNeo alone maintained a typical fibroblastic morphology with elongated and spindle-shaped cells (Fig. $6 \mathrm{~A}$ ). In contrast, clones obtained after transfection with both the LTR-Tax and pNeo plasmids and expressing functional Tax, as identified above, contained many cells with stellate morphology, abundant cytoplasm, and large cytoplasmic extensions (Fig. $6 \mathrm{~B}$ ).

To demonstrate conclusively that the functionally active Tax protein, as determined by HTLV-1 LTR transactivation, was capable of transactivation of the COL1A1 promoter, selected $\mathrm{Tax}+$ clones were transfected with $\mathrm{pAC} 171$ followed by deter- mination of CAT activity. Transactivation of the collagen promoter was evident in several Tax + clones as illustrated by one clone in Fig. 7. However, the level of HTLV-1 LTR activation, reflecting the production of functional Tax, did not correlate with transactivation of COL1A1 promoter.

Levels of type I procollagen and fibronectin mRNA in Tax+ stable clones. To investigate the effect of the Tax gene on the expression of the endogenous COL1A1 gene in the stably transfected clones, total RNA from three control and eight Tax + clones was extracted and examined by Northern hybridizations using a murine $\alpha 1$ (I) procollagen cDNA as a probe. The level of $\alpha 1$ (I) procollagen mRNA was on an average 4.5-fold higher in Tax + than in control clones, with a maximal increase of 11.4-fold in one clone (Fig. 8, $A$ and $C$ ). However, approximately one-half of the Tax + clones examined did not show an increase in the steady state levels for COL1A1. To determine whether the transactivation by Tax was confined to COL1A1 or extended to genes encoding other extracellular matrix proteins, we also analyzed the mRNA levels for fibronectin in six Tax + stable clones. The results shown in Fig. 8, $B$ and $D$, indicate that elevated fibronectin mRNA levels were observed in several $\mathrm{Tax}+$ clones in comparison to controls ( $\mathrm{pNeo}+$ clones). On an average, the fibronectin mRNA levels in Tax + clones were nearly threefold higher than in the two control clones, although two of the Tax + clones displayed greater than fourfold higher levels. It should be noted that the Tax + clones displaying the highest levels of $\alpha 1(\mathrm{I})$ procollagen mRNA (clones 1, 3, 5, and 6) also displayed the highest levels of fibronectin transcripts.

Collagen production in Tax+ stable clones. To examine whether the effects of Tax expression in the Tax + stable clones
A
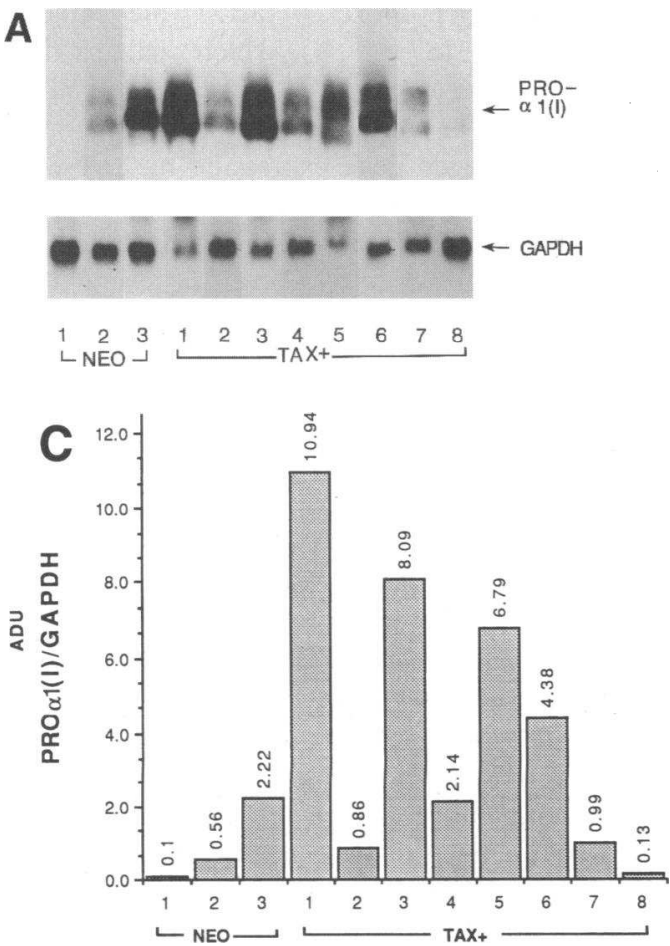

B
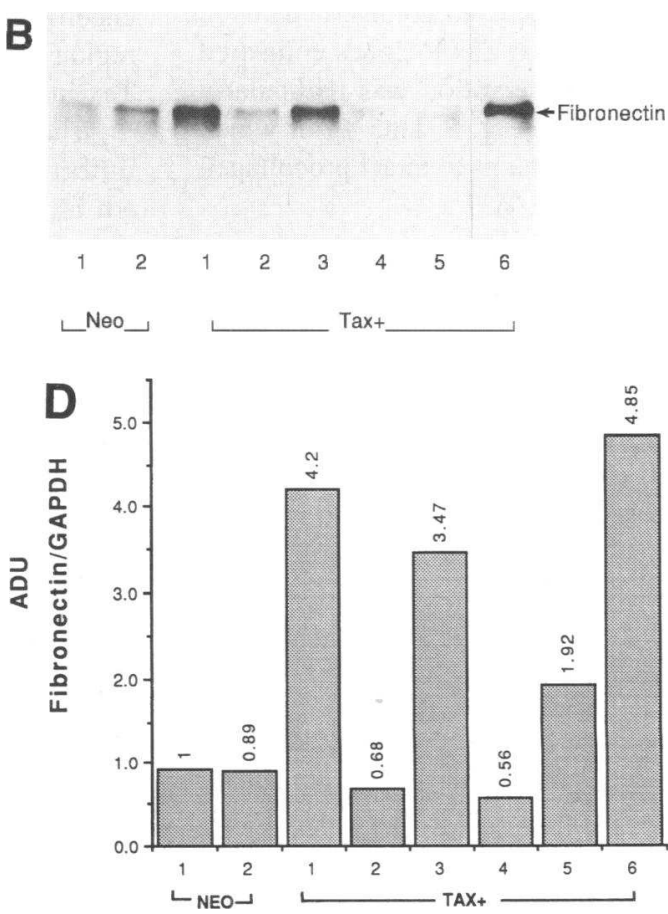

Figure 8. Northern analyses of total RNA prepared from stably transfected control and Tax + cell clones. Total RNA was extracted from Tax + and Neo+ control clones and $10 \mu \mathrm{g}$ of total RNA was electrophoresed in each lane. After transfer, the filters were hybridized to $(A)$ murine $\alpha 1(\mathrm{I})$ procollagen cDNA or $(B)$ murine fibronectin cDNA. Neo, neomycin-resistant control clones. Tax+, Tax producer clones. $(C$ and $D)$ Densitometric analyses of the Northern hybridizations shown in $A$ and $B$ respectively. 


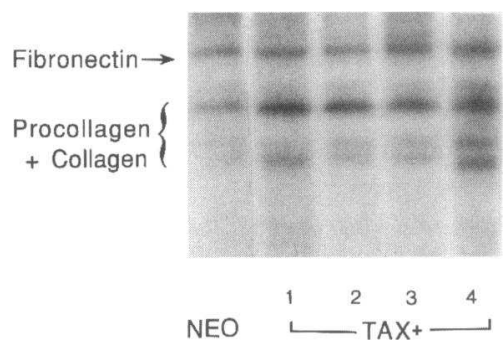

Figure 9. SDS-PAGE of $\left[{ }^{14} \mathrm{C}\right]$ proline extracellular matrix proteins synthesized in stable clones. NIH-3T3 cells were transfected with either pNeo alone or the pNeo plus LTR-Tax plasmid and stably transfected clones were established as described in Methods.

Cells from the stably transfected clones were cultured to confluency and then incubated for $24 \mathrm{~h}$ with $\left[{ }^{14} \mathrm{C}\right]$ proline. After dialysis, 50- $\mu 1$ aliquots of pooled medium and cell extract from each clone were used for the analysis. The figure represents fluorographs of SDS-PAGE of the radiolabeled media plus cell-associated proteins. $N E O$, Neomycinresistant control clone. TAX+, Tax + clones.

were also reflected at the protein level, collagen production was determined in four Tax + stable clones by biosynthetic labeling of confluent cultures of Tax + and control pNeo+ clones with $\left[{ }^{14} \mathrm{C}\right]$ proline and determination of collagenase-sensitive proteins. The results illustrated in Fig. 9 indicate that, compared to control pNeo+ clones, the Tax + stable clones produced higher levels of ${ }^{14} \mathrm{C}$-labeled proteins including $\left[{ }^{14} \mathrm{C}\right]$ collagen. Electrophoretic analysis of the samples indicated that the four Tax + stable clones which displayed elevated $\alpha 1$ (I) procollagen and fibronectin mRNA levels synthesized higher amounts of type I procollagen and fibronectin. Furthermore, a more efficient processing of procollagen precursors to mature collagen was apparent in the Tax + clones as indicated by the higher proportion of fully processed $\alpha 1$ and $\alpha 2$ collagen chains (as determined by comparison with the electrophoretic mobility of pure type I collagen $\alpha$ chains) relative to the intact procollagen chains. The average ratio of fully processed collagen chains to intact procollagen chains was 0.94 in $6 \mathrm{Tax}+$ clones compared to 0.55 in 3 control clones. This observation was particularly noticeable in samples from clone 6 (Fig. 9, lane 4) in which the ratio of fully processed collagen chains to intact procollagen chains was 1.57 .

\section{Discussion}

The human type $\mathrm{C}$ retrovirus HTLV-1 has been identified as the causative agent of adult $T$ cell leukemia and has been implicated in the etiology of a progressive demyelinating syndrome termed HTLV-1-associated myelopathy or tropical spastic paraparesis (for review see reference 27). Insights into the pathophysiology of adult $\mathrm{T}$ cell leukemia have emerged with the molecular analysis of HTLV-1 proviral isolates. Like other retroviruses, HTLV-1 contains dual LTR as well as the three structural genes gag, pol, and env. In addition, the HTLV-1 genome contains genes encoding the transregulatory proteins Tax and Rex that regulate viral gene expression (28). Tax functions as a potent transcriptional activator of the viral LTR leading to high levels of expression of all viral genes $(15,29$, 30 ). Furthermore, Tax was shown to stimulate the expression of several cellular promoters including those of IL-2 and its $\alpha$ receptor, GM-CSF, and c-fos (31-44). It has been further documented that Tax exerts its function on the transcription of these genes indirectly by altering the expression of certain host transcription factors. Altered activation of some members of the cAMP response element binding protein/activating transcription factor family has been reported as the mechanism responsible for the activation of HTLV-1 (39). TGF- $\beta 1$ and tissue inhibitor of metalloproteinase-1 appear to be Tax transactivated through promoter elements corresponding with activating protein 1 binding sites that are likely recognized by the Fos-Jun heterodimer $(43,44)$. Tax is thought to activate gene transcription by inducing activating protein 1 gene expression (38) and by promoting the dimerization of leucine zipper proteins, including activating protein 1 , and thus promoting binding to DNA $(45,46)$. Tax has also been shown to increase the DNA binding activity of other transcription factors including activating transcription factor/cAMP response-element binding protein, serum response factor, nuclear factor $-\kappa \mathrm{B}$, activating transcription factor 1 , and $\mathrm{Spl}(46)$. On the other hand, the induction of expression of a member of the nuclear factor $-\kappa \mathrm{B}$ family of proteins by Tax has been implicated in the activation of IL-2 and IL- $2 \alpha$ receptor genes $(40,41)$.

Our previous observations demonstrating that the HIV-1 transactivator protein was capable of inducing the expression of genes encoding extracellular matrix proteins in glioblastoma cells (13) led us to exarnine the biological effect of expression of the more potent transactivator protein, HTLV-1 Tax on the promoter activity of COL1A1 in NIH-3T3 cells. Our results demonstrated that NIH-3T3 cells expressing functional Tax displayed markedly increased activity of the COL1A1 promoter. Although the effects of Tax on COL1A1 were of a lower magnitude than its effects on other Tax-responsive cellular genes such as IL-2 or IL- $2 \alpha$ receptor (31-33), they were of similar magnitude as those of known activators of collagen gene expression such as TGF- $\beta(2,17)$. Transfection of deletion constructs of the COL1A1 promoter revealed that the region spanning nucleotides -174 to -84 appears to be involved in Tax-induced transactivation of the collagen promoter. In fact, a gene segment encompassing nucleotides -187 to -67 , which contains this region of the COL1A1 promoter, proved sufficient to confer Tax inducibility to an HSV tk promoter as shown in Fig. 4.

The stimulation of collagen gene expression by Tax was further demonstrated using Tax-producing stable clones. Northern blot hybridization analysis of total RNA demonstrated an elevation in the $\alpha 1$ (I) procollagen mRNA levels in several Tax producer clones. The effects of expression of the HTLV-1 Tax gene in NIH-3T3 cells were not confined to transactivation of the COL1A1 promoter and the concomitant elevation of the $\alpha 1$ (I) procollagen mRNA levels but appeared to extend to genes encoding other extracellular matrix proteins such as fibronectin. This was evidenced by increased levels of the corresponding transcripts in Tax + clones. These effects were reflected at the protein level as shown in biosynthetic studies of collagen and fibronectin production in Tax + clones. Of particular interest was the observation that procollagen processing into mature collagen chains was substantially accelerated in Tax + clones as demonstrated by the higher ratio of fully processed collagen $\alpha$-chains relative to intact procollagen. However, there was not a complete correlation between the activation of the HTLV-1 LTR and the collagen or fibronectin promoters. The variability in response of the endogenous collagen and fibronectin genes to Tax has not been investigated but may be related to dose effects, transfection efficiency, the site of integration of the HTLV-1 Tax, and the secondary effects that the insertion may have on other cellular genes. Furthermore, the differential response of the various promoters to Tax is not entirely unex- 
pected, as the level of expression of these genes would depend on the strength of their corresponding promoters as well as the differential responsiveness of each promoter to Tax transactivation.

The intimate mechanisms responsible for the increased promoter activity of COL1A1 in cells expressing functionally active Tax remain unclear. It is likely that these effects result from induction of specific transcription factors or the activation of preexisting ones, as is the case for other cellular genes activated by $\operatorname{Tax}(31-47)$. However, it is possible that these effects may be mediated by cytokines or growth factors whose production or activity is stimulated by Tax. In this context, it is important to consider the possibility that the effects we observed may be mediated by a Tax-induced increase in the production of TGF- $\beta$. Evidence is accumulating to indicate that expression of retroviral proteins can lead to increased production of this growth factor in vitro $(43,47,48)$ as well as in vivo in animals transgenic for the Tax gene $(14,49,50)$. Furthermore, the changes in collagen and fibronectin observed in $\mathrm{Tax}+\mathrm{NIH}-$ 3T 3 cells are similar to those caused by TGF- $\beta$ in mesenchymal cells (for review see reference 51), including an increase in the processing of procollagen as described previously in normal human dermal fibroblasts (52).

Studies are currently in progress to determine whether induction of various cytokines and growth factors, including TGF$\beta$, by Tax may play a role on the increased expression of genes encoding extracellular matrix proteins demonstrated here. The observations described here lead us to suggest that expression of certain viral proteins may play a role in the fibrosis that occurs in diseases such as systemic sclerosis and idiopathic pulmonary fibrosis in which increased extracellular matrix production and/or increased expression of cytokine genes (including those encoding TGF- $\beta 1$ ) have been demonstrated. The possibility that cellular expression of retroviral proteins may result in tissue fibrosis in vivo has been strengthened by the recent observation that transgenic mice expressing a noninfectious HIV-1 gene develop severe mesangial fibrosis $(14,53,54)$. Further studies to test this hypothesis may provide clues regarding the etiology and/or pathogenesis of systemic sclerosis and idiopathic pulmonary fibrosis.

\section{Acknowledgments}

The excellent assistance of $\mathrm{O}$. Ma and M. Mills in preparation of this manuscript is gratefully acknowledged.

This work was supported by National Institutes of Health grants AM-19616 (S. A. Jiménez) and AI-28272 (K. Khalili and S. Amini) and by a grant from the Scleroderma Federation (S. A. Jiménez).

\section{References}

1. Jimenez, S. A., G. Feldman, R. I. Bashey, R. Bienkowski, and J. Rosenbloom. 1986. Coordinate increase in the expression of type I and III collagen genes in progressive systemic sclerosis fibroblasts. Biochem. J. 237:837-843.

2. Raghu, G., S. Masta, D. Meyers, and A. S. Narayanan. 1989. Collagen synthesis by normal and fibrotic human lung fibroblasts and the effect of transforming growth factor-beta. Am. Rev. Respir. Dis. 140:95-100.

3. Slack, J. L.,D. J. Liska, and P. Bornstein. 1993. Regulation of expression of the type I collagen genes. Am. J. Med. Genet. 45:140-151.

4. Adams, S. L., M. E. Sobel, B. H. Howard, K. Olden, K. M. Yamada, B deCrombrugghe, and I. Pastan. 1977. Levels of translatable mRNAs for cell surface protein, collagen precursors, and two membrane proteins are altered in Rous sarcoma virus-transformed chick embryo fibroblasts. Proc. Natl. Acad. Sci. USA. 74:399-3403.

5. Howard, B. H., S. L. Adams, M. E. Sobel, I. Pastan, and B. de Crombrugghe.
1978. Decreased levels of collagen mRNA in Rous sarcoma virus-transformed chick embryo fibroblasts. J. Biol. Chem. 253:5869-5874.

6. Avvedimento, E.,Y. Yamada, E. Lovelace, G. Vogeli, B. de Crombrugghe, and I. Pastan. 1981. Decrease in the levels of nuclear RNA precursors for alpha 2 collagen in Rous sarcoma virus transformed fibroblasts. Nucleic Acids Res. 9:1123-1131.

7. Sandmeyer, S., B. Gallis, and P. Bornstein. 1981. Coordinate transcriptional regulation of type I procollagen genes by Rous sarcoma virus. J. Biol. Chem. 256:5022-5028.

8. Yoshimura, M., S. A. Jimenez, and A. Kaji. 1989. Effects of viral transformation on synthesis and secretion of collagen and fibronectin-like molecules by embryonic chick chondrocytes in culture. J. Biol. Chem. 262:1206-1209.

9. Sobel, M. E., T. Yamamoto, B. de Crombrugghe, and I. Pastan. 1981 Regulation of procollagen messenger ribonucleic acid levels in Rous sarcoma virus transformed chick embryo fibroblasts. Biochemistry. 20:2678-2684.

10. Frankel, A. D. 1992. Activation of HIV transcription by Tat. Curr. Opin. Gen. Dev. 2:293-298.

11. Siekevitz, M., M. B. Feinberg, N. Holbrook, F. Wong-Staal, and W. C. Greene. 1987. Activation of interleukin-2 and interleukin-2 receptor (Tac) promoter expression by the transactivator (tat) gene product of human T-cell leukemia virus, type I. Proc. Natl. Acad. Sci. USA. 84:5389-5393.

12. Bounaguro, L., G. Barillari, H. K. Chang, C. A. Bohan, V. Kao, R. Morgan, R. C. Gallo, and B. Ensoli. 1992. Effects of the human immunodeficiency virus type I Tat protein on the expression of inflammatory cytokines. J. Virol. 66:7159-7167.

13. Taylor, J. P., C. Cupp, A. Diaz, M. Chowdhury, K. Khalili, S. A. Jimenez, and S. Amini. 1992. Activation of expression of genes coding for extracellular matrix proteins in Tat-producing glioblastoma cells. Proc. Natl. Acad. Sci. USA. 89:9617-9621.

14. Nerenberg, M., S. H. Hinrichs, R. K. Reynolds, G. Khoury, and G. Jay. 1987. The tat gene of human T-lymphotropic virus type 1 induces mesenchymal tumors in transgenic mice. Science (Wash. DC). 237:1324-1329.

15. Sodroski, J. G., C. A. Rosen, and W. A. Haseltine. 1984. Trans-acting transcriptional activation of the long terminal repeat of human T-lymphotropic viruses in infected cells. Science (Wash. DC). 225:381-385

16. Law, M. -F., J. C. Byrne, and P. M. Howley. 1983. A stable bovine papillomavirus hybrid plasmid that expresses a dominant selective trait. Mol. Cell Biol. 3:2110-2115.

17. Jimenez, S. A., J. Varga, A. Olsen, L. Li, A. Diaz, J. Herhal, and J. Koch. 1994. Functional analysis of the human $\alpha 1$ (I) procollagen gene promoter. Differential activity in-collagen-producing and non-producing cells and response to transforming growth factor- $\beta 1$. J. Biol. Chem. 269:12684-12691.

18. Luckow, B., and G. Schutz. 1987. CAT constructions with multiple unique restriction sites for the functional analysis of eukaryotic promoters and regulatory elements. Nucleic Acids Res. 15:5490.

19. Graham, F. L., and A. J. van der Eb. 1973. A new technique for the assay of infectivity of human adenovirus 5 DNA. Virology. 52:456-467.

20. Gorman, C. M., L. F. Moffat, and B. H. Howard. 1982. Recombinant genomes which express chloramphenicol acetyl transferase in mammalian cells. Mol. Cell Biol. 2:1044-1051.

21. Southern, P. J., and P. Berg. 1982. Transformation of mammalian cells to antibiotic resistance with a bacterial gene under the control of the SV40 early region promoter. J. Mol. Appl. Genet. 1:327-341.

22. Sambrook, J., E. F. Fritch, and T. Maniatis. 1989. Molecular Cloning: A Laboratory Manual. 2nd ed. Cold Spring Harbor Laboratory, Cold Spring Harbor, NY. 7.18-7.22.

23. French, B. T., W. H. Lee, and G. G. Maul. 1985. Nucleotide sequence of a cDNA clone for mouse pro $\alpha 1$ (I) collagen protein. Gene (Amst.). 39:311-312.

24. Schwarzbauer, J. E., J. W. Tamkum, I. R. Lemisha, and R. O. Hynes. 1983. Three different fibronectin mRNA arise by alternative splicing within the coding region. Cell. 35:4221-431.

25. Fort, P. H., L. Marty, M. Piechscyzk, S. ElSabrouty, C. H. Deni, P. H. Jenteur, and J. M. Blanchard. 1985. Various rat adult tissues express only one major mRNA species from the glyceraldehyde-3-phosphate-dehydrogenase multigenic family. Nucleic Acids Res. 13:1431-1442.

26. Peterkofsky, B., and R. Diegelmann. 1971. Use of a mixture of proteinasefree collagenase for the specific assay of radioactive collagen in the presence of other proteins. Biochemistry. 10:988-994.

27. Hjelle, B. 1991. Human T-cell leukemia/lymphoma viruses. Arch. Pathol. Lab. Med. 115:440-450.

28. Smith, M. R., and W. C. Greene. 1991. Molecular biology of the type I human T-cell leukemia virus (HTLV-1) and adult T-cell leukemia. J. Clin. Invest. 87:761-766

29. Mathews, M. A. H., R. B. Markowitz, and W. S . Dynan. 1992. In vitro activation of transcription by the human T-cell leukemia virus type I Tax protein. Mol. Cell Biol. 12:1986-1996.

30. Marriott, S. J., I. Boros, J. F. Duvall, and J. N. Brady. 1989. Indirect binding of human T-cell leukemia virus type $\mathrm{I} \operatorname{Tax}_{1}$ to a responsive element in the viral long terminal repeat. Mol. Cell Biol. 9:4152-4160.

31. Inoue, J., M. Seiki, T. Taniguchi, S. Tsuru, and M. Yoshida. 1986. Induc- 
tion of interleukin- 2 receptor gene expression by $\mathrm{p} 40 \times$ encoded by human T-cell leukemia virus type I. EMBO (Eur. Mol. Biol. Organ.) J. 5:2883-2888.

32. Cross, S. L., M. B. Feinberg, J. B. Wolf, N. J. Holbrook, F. Wong-Staal, and W. J. Leonard. 1987. Regulation of the human interleukin-2 receptor $\alpha$ chain promoter: activation of a nonfunctional promoter by the transactivator gene of HTLV-1. Cell. 49:47-56.

33. Maruyama, M., H. Shibuya, H. Harada, M. Hatskeyoma, M. Seiki, T. Fujita, J. Inoue, M. Yoshida, and T. Taniguchi. 1987. Evidence for aberrant activation of the interleukin- 2 autocrine loop by HTLV-1-encoded p $40 \times$ and T3/ Ti complex triggering. Cell. 48:343-350.

34. Wano, Y., M. Feinberg, J. B. Hosking, H. Bogerd, and W. C. Greene. 1988. Stable expression of the Tax gene of type I human T-cell leukemia virus in human T cells activates specific cellular genes involved in growth. Proc. Natl. Acad. Sci. USA. 85:9733-9737.

35. Fujii, M., P. Senone-Corse, and I. M. Verma. 1988. c-fos promoter transactivation by the Tax 1 protein of human T-cell leukemia virus type I. Proc. Natl. Acad. Sci. USA. 85:8526-8530.

36. Ruben, S., H. Poteat, T. -S. Tan, K. Kowskami, R. Rolder, W. A. Haseltine and C. A. Rosen. 1988. Cellular transcription factors and regulation of IL-2 receptor gene expression by HTLV-Tax gene product. Science (Wash. DC). 241:89-92.

37. Lilienbaum, A., M. Duc Dodon, C. Alexandre, L. Gazzola, and D. Paulin 1990. Effect of human T-cell leukemia virus type I Tax protein on activation of the human vimentin gene. J. Virol. 64:256-263.

38. Fujii, M., T. Niki, T. Mori, T. Matsuda, M. Matsui, N. Nomura, and M Seiki. 1991. HTLV-1 Tax induces expression of various immediate early serum responsive genes. Oncogene. 6:1023-1029.

39. Franklin, A. A., M. F. Kubik, N. Uittenbogaard, A. Bransweiler, P. Utai sincharoen, M. -A. H. Matthews, W. S. Dynan, J. P. Hoeffler, and J. K. Nyborg. 1993. Transactivation by the human T-cell leukemia virus Tax protein is mediated through enhanced binding of activating transcription factor-2 (ATF-2) ATF response and cAMP element-binding protein (CREB). J. Biol. Chem. 268:2122521231

40. Zhao, L. H., and W. C. Griam. 1991. Interaction of the human T-cell lymphotropic virus type I (HTLV-1) transcriptional activator Tax with cellula factors that bind specifically to the 21-base-pair repeats in the HTLV-1 enhancer. Proc. Natl. Acad. Sci. USA. 88:11445-11449.

41. Albrecht, H., A. N. Shakhov, and V. Jongeneel. 1992. Transactivation of the tumor necrosis factor alpha promoter by the human T-cell leukemia virus type I Tax 1 protein. J. Virol. 66:6191-6193.

42. Smith, M. R., and W. C. Greene. 1990. Identification of HTLV-1 Tax transactivator mutants exhibiting novel transcriptional phenotypes. Genes \& Dev $4: 1875-1885$.
43. Kim, S. J., J. H., Kehrl, J. Burton, C. L. Tendler, K. T. Jeang, D. Danielpour, C. Thevenin, K. Y. Kim, M. B. Sporn, and A. B. Roberts. 1990. Transactivation of the transforming growth factor $\beta 1$ (TGF- $\beta 1$ ) gene by human T-lymphotropic virus type I Tax: a potential mechanism for the increased production of TGF- $\beta 1$ in adult T-cell leukemia. J. Exp. Med. 172:121-129.

44. Uchijima, M., H. Sato, M. Fujii, and M. Seiki. 1994. Tax proteins of human T-cell leukemia virus type 1 and 2 induce expression of the gene encoding erythroid-potentiating activity (tissue inhibitor of metalloproteinases-1, TIMP-1). J. Biol. Chem. 269:14946-14950.

45. Armstrong, A. P., A. A. Franklin, M. N. Uittenbogaard, H. A. Giebler, and J. K. Nyborg. 1993. Pleiotropic effect of the human T-cell leukemia virus Tax protein on the DNA binding activity of eukaryotic transcription factors. Proc. Natl. Acad. Sci. USA. 90:7303-7307.

46. Warner, S., and M. R. Green. 1993. Tax protein stimulation of DNA binding of bZIP protein by enhancing dimerization. Science (Wash. DC). 262:395-399.

47. Tendler, C. L., S. J. Greenberg, J. D. Burton, D. Danielpour, S. J. Kim A. Blattner, A. Manns, and T. A. Waldmann. 1991. Cytokine induction in HTLV-1 associated myelopathy and adult T-cell leukemia: alternate molecular mechanisms underlying retroviral pathogenesis. J. Cell Biochem. 46:302-311.

48. Cupp, C., J. P. Taylor, K. Khalili, and S. Amini. 1993. Evidence for stimulation of the transforming growth factor- $\beta 1$ promoter by HIV-1 Tat in cells derived from CNS. Oncogene. 8:2231-2236.

49. Hinrichs, S. H., M. Nerenberg, R. K. Reynolds, G. Khoury, and G. Jay. 1987. A transgenic mouse model for human neurofibromatosis. Science (Wash DC). 237:1340-1343.

50. Kim, S. J., T. S. Winokur, H. D. Lee, D. Danielpour, K. Y. Kim, A. G. Geiser, L. S. Chen, M. B. Sporn, A. B. Roberts, and G. Jay. 1991. Overexpression of transforming growth factor- $\beta$ in transgenic mice carrying the human T-cell lymphotropic virus type I Tax gene. Mol. Cell Biol. 11:5222-5228.

51. Roberts, A. B., U. I. Heine, K. C. Flanders, and M. B. Sporn. Transforming growth factor-beta. Major role in regulation of extracellular matrix. Ann. NY Acad. Sci. 580:225-232.

52. Varga, J., and S. A. Jiménez. 1986. Stimulation of normal human fibroblast collagen production and processing by transforming growth factor- $\beta$. Biochem. Biophys. Res. Commun. 138:974-980.

53. Kopp, J. B., M. E. Klotman, S. H. Adler, L. A. Bruggeman, P. Dickie, N. J. Marinos, M. Eckhaus, J. L. Bryant, A. L. Notkins, and P. E. Klotman. 1992 Progressive glomerulosclerosis and enhanced renal accumulation of basement membrane components in mice transgenic for human immunodeficiency virus type I genes. Proc. Natl. Acad. Sci. USA. 89:1577-1581.

54. Dickie, P., J. Felser, M. Eckhaus, J. Bryant, J. Silver, N. Marinos, and A. L. Notkins. 1991. HIV-associated nephropathy in transgenic mice expressing HIV-1 genes. Virology. 185:109-119. 